\title{
Políticas públicas relacionadas à diversidade sexual na escola
}

\author{
Amanda Nogara Marcon \\ Universidade Federal de Santa Catarina - Florianópolis - SC - Brasil \\ Luísa Evangelista Vieira Prudêncio \\ Universidade Federal de Santa Catarina - Florianópolis - SC - Brasil \\ Marivete Gesser \\ Universidade Federal de Santa Catarina - Florianópolis - SC - Brasil
}

\begin{abstract}
Resumo
Atualmente vêm ocorrendo mudanças significativas nas políticas governamentais relacionadas à diversidade sexual na escola. Essas políticas estão cada vez mais alinhadas com os preceitos dos direitos humanos e da inclusão na diversidade. O objetivo desta pesquisa foi o de analisar a produção de conhecimento em diversidade sexual na escola desde a publicação dos Parâmetros Curriculares Nacionais, focando-se na relação entre os documentos oficiais e em como é produzido o conhecimento, no conceito de gênero utilizado neste processo, bem como no mapeamento, por meio de tal produção, das práticas educativas. Para a obtenção das informações, foi realizada uma revisão integrativa do conhecimento que abrangeu artigos científicos publicados nas bases de dados SciELO, PePSIC e Lilacs entre os anos de 1997 e 2013 . As informações obtidas evidenciam que os conhecimentos produzidos pelos estudos analisados estão cada vez mais alinhados aos preceitos dos direitos humanos, embora as práticas no interior da escola precisem avançar muito para a promoção de uma educação inclusiva da diversidade de modos de vivenciar a sexualidade.
\end{abstract}

Palavras-Chave: Sexualidade; educação; psicologia.

\section{Public policies related to sexual diversity in school}

\begin{abstract}
Currently the changes have occurred in government policies related to sexual diversity in school. These policies are increasingly aligned with the principles of human rights and inclusion in diversity. The objective of this research was to analyze the production of knowledge on sexual diversity in school since the publication of the National Curriculum Standards, focusing on the relationship between the official documents and how it is produced knowledge, the concept of gender used in this process, and mapping, by means of such production, educational practices. To obtain the information, an integrative review of the knowledge of scientific papers published in the databases SciELO was performed PePSIC and Lilacs between the years 1997 and 2013. The information obtained evidence that the knowledge produced by the analyzed studies are increasingly aligned with the principles of human rights, although the practices within the school need to move a lot to the promotion of inclusive education of diversity by the ways of experiencing sexuality.
\end{abstract}

Keywords: Sexuality; education; psychology.

\section{Políticas públicas relacionadas a la diversidad sexual en la escuela}

\section{Resumen}

Actualmente viene ocurriendo cambios significativos en las políticas gubernamentales relacionadas a la diversidad sexual en la escuela. Esas políticas están cada vez más en consonancia con los preceptos de los derechos humanos y de la inclusióne n la diversidad. El objetivo de este estudio fue el de analizar la producción de conocimiento en diversidad sexual en la escuela desde la publicación de los Parámetros Curriculares Nacionales, centrándose en la relación entre los documentos oficiales y en cómo es producido el conocimiento, en el concepto de género utilizado en este proceso, así como en el mapeo, por intermedio de tal producción, de las prácticas educativas. Para la obtención de las informaciones, se realizó una revisión integrativa del conocimiento que abarcó artículos científicos publicados en las bases de datos SciELO, PePSIC y Lilacs entre los años de 1997 y 2013. Las informaciones obtenidas evidencian que los conocimientos producidos por los estudios analizados están cada vez más en consonancia a los preceptos de los derechos humanos, aunque las prácticas en el interior de la escuela necesiten avanzar mucho para la promoción de una educación inclusiva de la diversidad de modos de vivenciar la sexualidad.

Palabras clave: Sexualidad; educación; psicología. 


\section{Introdução}

Hoje há um grande avanço nas políticas governamentais voltadas à garantia dos direitos sexuais e reprodutivos. Nesse cenário, a escola é considerada um locus privilegiado de valorização da diversidade de expressões de sexualidade, além de sua já reconhecida função social de promoção da cidadania e redução da vulnerabilidade social dos jovens. Todavia, autores como Alós (2011), Costa (2012), Toneli (2006), Louro (2001) e Junqueira, (2009) têm apontado que as práticas pedagógicas no âmbito da diversidade sexual, ao contrário do que preveem as políticas, têm fomentado a patologização e o preconceito às pessoas que divergem do modelo heteronormativo de sexualidade. Diante desse debate, este artigo, que propõe uma revisão integrativa, tem como objetivo caracterizar a produção do conhecimento científico relacionada à diversidade sexual no âmbito da escola por meio da análise: a) das relações entre o conhecimento produzido e os documentos oficiais voltados à garantia dos direitos sexuais na escola; b) do modo como o gênero é conceituado na produção do conhecimento relativa a esse tema, e c) da identificação do impacto das políticas e dos documentos recentes sobre o tratamento das questões de gênero e diversidade sexual na escola.

A escola apresenta-se como campo de atuação do psicólogo, na medida em que este profissional se compromete com a tarefa de construir um processo educacional no qual sejam favorecidos os processos de humanização. A sua formação pode agregar novos valores ao trabalho educacional, uma vez que o habilita a compreender as relações entre subjetividades e práticas escolares, e entre os processos psicológicos e pedagógicos. Ademais, a prática do psicólogo no campo da educação sexual pode auxiliar na desconstrução de patologizações dos diferentes modos de viver a sexualidade, favorecendo a reapropriação da capacidade de pensamento crítico dos indivíduos (Meira, Queiroz, Oliveira, Moraes, \& Oliveira, 2006).

Nessa mesma direção, Gesser, Oltramari, Cord e Nuernberg (2012) destacam a contribuição do psicólogo no processo de formação de educadores, uma vez que estes se constituíram sujeitos atravessados por valores morais, religiosos e biomédicos os quais patologicizam as expressões de sexualidade não heterossexuais. Diante disso, os autores ressaltam a importância de a Psicologia contribuir com o processo de formação de educadores - por meio de uma perspectiva ético-política de sexualidade, com a desconstrução das significações de gênero e sexualidade ancoradas na heteronormatividade - para a desnaturalização das violências, a ampliação da autonomia, a garantia dos direitos sexuais e reprodutivos e a diminuição da vulnerabilidade dos sujeitos da educação.

A produção de conhecimento sobre diversidade sexual na escola é recente. Ao categorizar os artigos selecionados, percebemos uma produção brasileira maior nos últimos seis anos. São muitos os estudos que justificam a relevância de se aprofundar o tema relacionado à diversidade sexual na escola. O estudo realizado por Asinelli-Luz e Cunha (2011), com base nos dados de estudantes com idades entre 16 e 25 anos disponíveis no questionário socioeconômico do Exame Nacional do Ensino Médio entre 2004 e 2008, identificou que os estudantes que não relatam ter sido alvos da discriminação homofóbica avaliaram sua experiência escolar de forma mais positiva que seus pares que experienciaram essa discriminação. Carrara e Ramos (conforme citado por Bento, 2011) revela um dado alarmante levantado em pesquisas realizadas nas paradas do Orgulho Gay, nas quais $40,4 \%$ dos 629 jovens entre 15 e 18 anos que foram entrevistados relataram terem sido vítimas de marginalização dentro do ambiente escolar.

As pesquisas acima citadas mostram a relevância de se discutir as questões relacionadas à homofobia nas escolas. Junqueira (2009) destaca que, tendo em vista que qualquer tipo de preconceito restringe a autonomia de determinados sujeitos ou grupos, é necessário que os educadores desconstruam seus próprios preconceitos para que não se perpetue uma educação de exclusão. "Dar-se conta de que o campo da educação se constituiu historicamente como um espaço disciplinador e normalizador é um passo decisivo para se caminhar rumo à desestabilização de suas lógicas e compromissos (Junqueira, 2009, p.14)". A escola ainda está estruturada para quem se enquadra dentro da heteronormatividade e ao mesmo tempo utiliza-se dos que são colocados à margem para sustentar a 'normalidade'. No espaço escolar, dessa forma, o modelo hegemônico de masculinidade é reforçado, sendo a violência a principal forma de expressão (Junqueira, 2009).

As diversas formas de violência relacionadas à diversidade sexual evidenciam a importância deste tema ser abordado de forma ética e política no contexto escolar. Todavia, embora a lei brasileira preveja a educação sexual nas escolas desde 1928, as ações realizadas apresentavam, até o fim do século passado, um caráter predominantemente higienista. Ademais, ainda que o nosso estado seja formalmente laico, diversos estudos têm mostrado o predomínio de concepções morais e religiosas norteando a implementação das políticas educacionais (Costa \& Ribeiro, 2011; Avila, Toneli, \& Andaló, 2011; Nardi \& Quartiero, 2012; Gesser \& cols., 2012).

A manutenção desses binarismos e fundamentalismos nas práticas pedagógicas, os quais oprimem as sexualidades divergentes no modelo heteronormativo, limita a garantia dos direitos sexuais e reprodutivos. Ao trabalhar a relação entre discriminação indireta e homofobia, Rios (2009) aponta que em uma cultura heterossexista, as condutas individuais e dinâmicas institucionais reproduzem o tempo todo, de forma não-intencional e despercebida, o parâmetro da heterossexualidade hegemônica como norma social e cultural. Tal naturalização acaba por distinguir, restringir, excluir e ou não-reconhecer os direitos humanos e liberdades individuais daqueles que não se adequam a esse parâmetro. Para o autor, essa forma de discriminação indireta, reproduzida nos pormenores das condutas diárias pessoais, culturais e burocráticas relaciona-se com a discriminação institucional. Nesse sentido, a dimensão social e 
a "normalidade" por ela produzida têm papel de destaque no que diz respeito à perpetuação de atos discriminatórios, ainda que os indivíduos e as instituições rejeitem conscientemente essa prática. Diante disso, considera-se que a problematização desse fenômeno é de extrema relevância para que os direitos humanos sejam garantidos e discutidos em todos os âmbitos.

Destaca-se também que estudar a temática da diversidade sexual é de grande importância para a busca de estratégias políticas voltadas ao rompimento de uma onda de conservadorismo que impera no Brasil e no mundo. Hoje temos, de um lado, os movimentos sociais voltados à luta pela igualdade de direitos civis a pessoas homossexuais e, de outro, políticos altamente conservadores e calcados em convicções morais e religiosas defendendo propostas voltadas à patologização das sexualidades não heterossexuais. Um efeito da atuação desses últimos foi a retirada das questões de gênero no Plano Nacional de Educação no ano de 2015 , tema que necessita ser mais estudado em outras produções.

A realização de pesquisas sobre diversidade sexual na escola também poderá contribuir para avaliar se os estudos que abrangem questões relacionadas ao tema têm considerado o gênero como uma categoria constituinte do preconceito e da homofobia àqueles que expressam comportamentos que divergem do padrão hegemônico de orientação sexual. Além disso, poderá contribuir para a identificação de subsídios teórico-metodológicos voltados à formação de educadores e à implementação de políticas públicas relativas à prevenção e combate à homofobia a partir de uma perspectiva ético-política de sexualidade.

\section{Método}

A pesquisa caracteriza-se como um estudo de revisão integrativa. Essa proposta metodológica é uma modalidade de trabalho investigativo na qual se busca reunir e sintetizar resultados de pesquisas sobre um determinado tema ou questão, permitindo organizar e aprofundar o conhecimento científico de uma área do saber científico (Mendes, Silveira, \& Galvão, 2008). Destaca-se que esse modelo de sistematização e análise de informações científicas tem sido bastante difundido no campo da pesquisa em saúde (Silveira \& Zago, 2006; Girondi \& Santos, 2011). Sua aplicação pode ser utilizada tanto para o delineamento de subsídios para a intervenção profissional, facilitando o acesso ao conhecimento por parte de não pesquisadores, quanto para a elaboração de uma síntese consistente da produção científica relativa a um determinado assunto visando indicar caminhos futuros para a investigação.

A revisão integrativa compreende uma série de etapas, iniciadas a partir da delimitação dos objetivos, os quais determinarão os critérios de inclusão e exclusão do material a ser colhido e analisado (Girondi \& Santos, 2011). No caso desta pesquisa, tais critérios se pautam pela necessidade de enfocar estudos publicados a partir da data de publica- ção do caderno intitulado "Orientação Sexual" referente aos Parâmetros Curriculares. Dessa forma, definiu-se o levantamento de referências com origem no ano de 1997 até as publicações de 2013.

Optou-se por selecionar apenas os estudos que apresentassem validade metodológica, publicados em periódicos científicos nacionais e reconhecidos na comunidade acadêmica da Educação, da Saúde e da Psicologia. As bases de dados disponíveis na internet SciELO, PePSIC e Lilacs foram fundamentais para a coleta de dados. A meta foi encontrar todos os artigos nacionais publicados que versassem sobre diversidade sexual no âmbito da educação e que se enquadrassem nos critérios desta pesquisa. Os artigos que se repetiram foram considerados somente uma vez.

Como critério de busca, utilizaram-se vocabulários estruturados ou descritores e/ou palavras-chave listados em thesaurus da área de Educação (Brasil, 2012) e Saúde (Bireme, 2012). O uso desse procedimento ofereceu mais garantia e segurança quanto à precisão da busca de artigos em sua coerência com os objetivos desta pesquisa. Elegeram-se artigos científicos que continham pelo menos um descritor no resumo e nas palavras-chave em sete conjuntos de termos: gênero, sexualidade, homofobia, diversidade sexual, orientação sexual, heteronormatividade e heterossexismo, todos acompanhados pelo descritor "escola".

A etapa seguinte consistiu na leitura e análise do texto integral. Após os cumprimentos dos critérios de seleção e exclusão, foram detectados 48 artigos que transitavam na interface das áreas da educação, saúde e psicologia.

Utilizou-se um formulário - criado pelas autoras desta revisão - como um procedimento de pré-categorização, o qual possibilitou subsidiar a análise e, posteriormente, o agrupamento dos estudos em unidades temáticas. $A$ inserção dos dados no formulário respeitava a seguinte seriação: tema do artigo, objetivo, método, sujeitos da pesquisa, referência pela APA, resumo, palavras-chave, assuntos abordados, principais conceituações referentes aos marcadores utilizados na busca dos artigos e relação do artigo com as políticas públicas.

A partir da análise do formulário, os resultados foram estruturados nos seguintes eixos temáticos: políticas públicas vigentes no âmbito da diversidade sexual na escola; conceituação de gênero de acordo com os artigos encontrados; e investigação das práticas referentes à diversidade sexual na escola pela produção do conhecimento levantada a partir da revisão. A interpretação dos dados obtidos foi ancorada a partir de autores que versam sobre a temática diversidade sexual na escola e suas interfaces, dentre eles: Louro (2001), Butler (1999), Figueiró (2009), Borges e Meyer (2008). Tais autores, ao avaliarem os processos históricos de pedagogização, patologização e medicalização da diversidade sexual na escola, permitem subsídios para a realização de uma avaliação crítica desse campo, bem como para delimitar pressupostos teórico-metodológicos voltados à promoção de práticas educativas ancoradas nos pressupostos dos direitos humanos. 


\section{Resultados}

\section{Políticas públicas sobre a diversidade sexual na escola}

Neste eixo temático será mostrada a relação da produção do conhecimento sobre diversidade sexual na escola com as políticas públicas voltadas à garantia dos direitos sexuais e reprodutivos no ambiente escolar. Por meio da análise desta relação, espera-se avaliar o impacto dos documentos e programas do governo no âmbito acadêmico.

A partir da década de 90 , surgiram importantes políticas governamentais relacionadas à abordagem da sexualidade na escola visando tanto à prevenção de doenças e promoção de saúde como também à garantia dos direitos sexuais e reprodutivos (Nardi \& Quartiero, 2012). Entre os documentos que apoiam a atuação profissional nesse campo, destacam-se: a) Parâmetros Curriculares Nacionais (1998); b) Estatuto da Criança e do Adolescente (Lei 8.069/90); c) Plano Nacional de Políticas para as Mulheres (Brasil, 2004a); d) Programa Brasil Sem Homofobia (Brasil, 2004b); e) Programa Gênero e Diversidade na Escola (2008), e f) Programa de Saúde na Escola - PSE (Brasil,2007).

Com relação aos estudos analisados, constatou-se que, das 48 produções acadêmicas investigadas, apenas sete eram estudos que analisavam a implementação de práticas/experiências pautadas nas políticas públicas existentes; 24 se propuseram a desenvolver subsídios teórico-metodológicos voltados ao aperfeiçoamento ou implementação das políticas e 17 não citavam qualquer relação com as políticas existentes.

Os sete trabalhos que analisaram a implementação de políticas públicas buscaram investigar: o "Programa de Formação de Professoras/es em Gênero e Diversidade nas Escolas (GDE)" (Rohden, 2009); o "Programa Nacional dos Livros Didáticos (PNLD) (Fontes, 2008; Lionço \& Diniz, 2008; Rios \& Santos, 2008; Vianna \& Ramires, 2008); o "Projeto de Formação Educando para a Diversidade (realizado pela ONG Nuances, financiada pelo Brasil Sem Homofobia) (Nardi \& Quartiero, 2012), e o "Programa Brasil Sem Homofobia" (Borges \& Meyer, 2008). Acredita-se que a análise da implementação desses programas é de fundamental importância, uma vez que, em suas propostas, propõem romper com os discursos sexistas e heteronormativos que, segundo autores como Louro (2001), Alos (2011) e Gesser, Oltramari e Panison (2015), atravessam e constituem as práticas educativas na contemporaneidade.

No que se refere aos artigos que se propunham a desenvolver subsídios teórico-metodológicos voltados ao aperfeiçoamento ou à implementação das políticas públicas voltadas à garantia dos direitos sexuais e reprodutivos, constatou-se que grande parte deles - no total 15 dos 24 - apoiam-se nos Parâmetros Curriculares Nacionais (PCN), lançados em 1997. Isso evidencia que esse documento, embora ainda não incorporado em todas as produções, teve um impacto significativo na produção do conhecimento na área, conforme já apontado por Nardi e Quartiero (2012).

Optou-se por analisar a relação entre os anos em que se observou um maior número de publicações (2008, 2011 e 2012) e as políticas públicas citadas nesses artigos, uma vez que 31 das 48 publicações concentram-se nesses períodos. Destaca-se que, no ano de 2008, as produções analisadas foram relacionadas às políticas: "Brasil Sem Homofobia", "Parâmetros Curriculares Nacionais" e "Programa Nacional do Livro Didático". Em 2011, os estudos continuam se apoiando majoritariamente nos "PCN" e no "Programa Brasil sem Homofobia". O ano de 2012 apresenta o mesmo resultado; contudo, traz o Plano Nacional de Políticas para as Mulheres como nova política de apoio para as produções acadêmicas. Constata-se, a partir dos dados analisados, que os Parâmetros Curriculares Nacionais são a política de maior influência nas produções de conhecimento relacionadas à diversidade sexual e educação. Apesar de não terem peso de lei, os PCN padronizaram os currículos escolares brasileiros e, segundo Gesser e cols. (2012), ainda ocupam, no cenário atual, o papel de 'norteadores' das atividades desenvolvidas no âmbito escolar, refletido pelo número de estudos que ainda se baseiam no documento.

Considerando que os PCN sugerem que a temática da orientação sexual e sexualidade seja trabalhada de forma transversal em todas as disciplinas e articulada a outros temas, como ética, saúde, gênero, ecologia e pluralidade cultural (Nardi, 2008), destaca-se como muito relevante a produção de conhecimentos voltada ao seu aperfeiçoamento.

A partir das análises, identificou-se que outra política que mostrou ter bastante influência nas produções acadêmicas é o "Programa Brasil sem Homofobia", a qual embasou 10 dos 31 estudos relacionados às políticas públicas. Tal proposta insere o tema da diversidade sexual no espaço escolar e traz a discussão da igualdade de gênero, identidade de gênero e orientação sexual. Essa política, lançada em 2004, busca fortalecer a perspectiva dos direitos sexuais como direitos humanos, situando a sexualidade entre os direitos fundamentais para o exercício pleno da cidadania (Borges \& Meyer, 2008).

Também foram identificados artigos que se propõem a oferecer subsídios para o Programa Nacional do Livro Didático (PNLD) e o Programa Nacional do Livro Didático para o Ensino Médio (PNLEM), de modo a garantir que a diversidade sexual seja contemplada pelos livros didáticos. Os estudos de Fontes (2008), Vianna e Ramires (2008) e Lionço e Diniz (2008), também objetos desta pesquisa, apontaram a predominância do modelo heteronormativo de família nos materiais distribuídos pelos programas, o que evidencia a dificuldade de implementação dos PCN e demais políticas voltadas à prevenção da homofobia.

Embora os estudos analisados nesta pesquisa tendam a apontar que a heteronormatividade ainda continua muito presente no cotidiano escolar, o estudo realizado por Asinelli-Luz e Cunha (2011), a partir dos dados de 6.414.302 estudantes com idade entre 16 e 25 anos disponíveis no questionário socioeconômico do ENEM, indicou um decrés- 
cimo na invisibilidade da homofobia a partir do estímulo de ações de promoção dos direitos humanos, o que evidencia que as políticas voltadas à prevenção e combate à homofobia têm contribuído para visibilizar esse tipo de preconceito. Os autores da pesquisa destacaram que não foi possível verificar se essa mudança ocorre também quanto ao percentual de concluintes que afirmam que se sentiriam incomodados ao conviver com homossexuais, já que essa variável não foi coletada no questionário do ENEM 2004.

Percebe-se, então, que a criação de políticas públicas voltadas à diversidade sexual na escola fomenta a discussão acadêmica para verificar como se dá a aplicação prática das políticas e dos documentos oficiais. Ainda assim, destaca-se que há um grande abismo entre o que propõe a política e a efetividade na sua implementação, uma vez que a maior parte dos estudos analisados apontou que as desigualdades de gênero e a heteronormatividade continuam muito presente nas escolas, conforme será analisado no terceiro tópico dos resultados.

\section{Conceito de gênero na produção do conhecimento sobre diversidade sexual na escola}

O conceito de gênero surge como fundamental na produção de conhecimento sobre diversidade sexual na escola. As práticas no ambiente escolar são cotidianamente atravessadas por discursos os quais naturalizam a concepção binária de sexo e gênero, concepção que, por sua vez, naturaliza a expressão heteronormativa de sexualidade como saudável e patologiciza as que dela divergem. Asinelli-Luz e Cunha (2011) propõem que gênero deve ser um tema central e amplamente discutido no ambiente escolar, para que os educadores tenham a oportunidade de refletir sobre até que ponto suas práticas contribuem para manter ou desconstruir discursos dominantes em relação à sexualidade. Diante disso, torna-se relevante investigar quais as concepções de gênero presentes nas produções acadêmicas, uma vez que essas atravessam e constituem a práxis da educação.

Costa (2012) mostra que há uma estreita relação entre o preconceito de orientação sexual e o preconceito de gênero, justificando-se, portanto, a escolha do assunto revisado. O autor, com base no estudo de revisão bibliográfica, constatou que a afirmação da identidade masculina heterossexual é construída pela negação das demais orientações sexuais, em busca da aprovação de seus pares, desvelando-se, então, em violência e preconceito de gênero. Essa questão também é apontada por Toneli (2006), quando destaca que, para reafirmar a sua sexualidade, o homem se distancia e busca rechaçar todas as expressões que remetem ao que é caracterizado como feminino, contribuindo para a configuração da homofobia.

Considerando os critérios de inclusão e exclusão, conforme já destacado, foram analisados e categorizados ao total 48 artigos com a temática diversidade sexual na escola entre os anos 1997 e 2013, ressaltando que tal busca ocorreu apenas a partir das bases de dados citadas no método. Ao categorizar o marco conceitual dos estudos, observou-se a predominância da conceituação de gênero, sendo que, dos 48 artigos, 20 o conceituam. No que se refere aos demais conceitos, os quais englobam a discussão acerca da diversidade sexual, 17 conceituam sexualidade e 14, homofobia. Já os termos heteronormatividade, heterossexismo, diversidade sexual e orientação sexual foram conceituados em menos artigos.

Em relação aos vinte textos que continham a conceituação de gênero, verificou-se que há uma hegemonia da perspectiva pós-estruturalista e de suas derivações como Estudos Culturais, construcionistas e teoria queer, uma vez que todos os estudos mencionados apresentavam tal viés teórico. Sob a perspectiva dos demais conceitos investigados nessa revisão, gênero é o marcador conceitual que mais se destaca. Ainda assim, deve-se apontar para a sua insuficiente teorização presente nos artigos, uma vez que apenas $45 \%$ destes esclarecem a sua definição. No restante dos estudos que se propõe a dialogar com gênero, a definição e compreensão teórica do mesmo aparece ora implícita no texto, ora indelineável.

Considerando a relação entre o preconceito de gênero e fenômenos reproduzidos na escola como o sexismo e a homofobia, destaca-se o potencial político de os artigos neste campo problematizarem as questões relacionadas à diversidade sexual na escola fundamentando-os no conceito de gênero. Isso porque, com base na afirmação de Butler (2006), a teoria, juntamente com as intervenções em níveis políticos e sociais, tem um potencial transformador da realidade. Dessa forma, destaca-se a importância de os estudos apresentarem fundamentos teóricos para que esses contribuam com a transformação das políticas e práticas instituídas.

Os artigos que fundamentam suas análises na teoria pós-estruturalista apresentam importantes contribuições para o campo da diversidade sexual na escola. Essa perspectiva aponta a necessidade de romper o esquema tradicional das tradições filosóficas ocidentais, pautadas em uma estrutura dicotômica de pensamento, para então poder desconstruir o pensamento binário. Tal rompimento com os binarismos e fundamentalismos abre espaço para a valorização da diversidade das expressões de gênero e sexualidade, produzindo um efeito de despatologização daquilo que antes era norma (Mariano, 2005). Os autores ancorados no pós-estruturalismo destacam que essa teoria contribui para a perspectiva política de gênero, à medida que questiona categorias unitárias e universais que costumam ser encaradas como naturais, como o ser "homem" e ser "mulher", para torná-las construções históricas.

A pesquisa indicou que gênero, na perspectiva pós-estruturalista, é compreendido como uma construção discursiva, histórica e cultural e não mais uma categoria natural ou dada a partir do sexo biológico (Beiras, Tagliamento, \& Toneli; 2005; Bento, 2011; Dinis, 2008; César, 2009; Cruz, 2011; Félix \& Palafox, 2009; Ferrari \& Almeira, 2012; Furlani, 2007; Gesser e cols., 2012; Gomes, 2006; 
Lionço \& Diniz, 2008; Maia, Navarro \& Maia, 2011; Quirino \& Rocha, 2012; Rosistolato, 2009; Rohden, 2009; Alós, 2011; Toneli, 2006; Wenetz, Stigger \& Meyer, 2013; Wenetz, 2012). Portanto, com base nessa perspectiva, não são as características sexuais que marcam as diferenças entre homens e mulheres, mas o modo como elas são representadas e valorizadas na sociedade.

Observou-se também que muitos dos artigos analisados, quando abordam o conceito de gênero, dão destaque às relações de poder (Furlani, 2007; Gomes, 2006; Maia \& cols. 2011; Rohden, 2009). Essas relações de poder são compreendidas como inscritas na linguagem, e são aspectos importantes na compreensão das construções de gênero como produção cultural.

Também há autores que relacionam gênero com pedagogias culturais. Nesta seara, destacam-se os trabalhos de Louro (1999) e Alós (2011). A pedagogização dos corpos e das sexualidades consiste em um processo por meio do qual as práticas pedagógicas direcionam os gêneros e as sexualidades à reprodução do modelo da heteronormatividade. Esse processo está presente nos variados contextos sociais e contribui para a manutenção de binarismos e fundamentalismos relacionados ao gênero e à sexualidade.

Portanto, no que se refere à conceituação de gênero presente nos artigos analisados, observou-se uma preocupação dos autores em romper perspectivas teóricas naturalizantes e essencializantes, bem como a busca de um marco conceitual que enfatiza o caráter histórico e político deste conceito.

\section{As práticas referentes à diversidade sexual na escola na produção do conhecimento analisada}

A pesquisa identificou que 34 dentre os 48 artigos categorizados embasavam seus estudos a partir da análise das práticas educativas. Com relação a essas práticas, consideraram-se: oficinas que trabalhassem a temática da sexualidade (três artigos); grupos com professores que discutiam as suas ações em sala de aula (oito artigos); análise dos livros didáticos oferecidos pelo PNLD (seis artigos); estudos etnográficos em salas de aula (13 artigos), entre outros projetos de educação sexual (quatro artigos).

As análises realizadas a partir dos artigos obtidos nas bases de dados demonstraram que, no contexto escolar, ainda é predominante a reprodução de práticas heteronormativas. Esse fato corrobora o estudo realizado por Gesser, Oltramari e Panison (2015) com o objetivo de identificar as concepções de sexualidade de professores de escolas de uma capital do sul do Brasil. Neste, os autores identificaram a presença de três concepções de sexualidade, a saber, a heteronormativa, a preventivista e, em um número menor de enunciações, a relativa a democracia sexual ${ }^{1}$. Ademais, também foi identificado

1 De acordo com Eric Fassin (2009), a "democracia sexual é a extensão do domínio democrático às questões sexuais, ou seja, da introdução dos valores de liberdade e igualdade num domínio antes relegado à esfera privada, mantido fora da história e da política, numa cultura e mesmo numa natureza imutável" (Fassin, 2009, que apenas $22 \%$ dos professores conheciam os $\mathrm{PCN}$, o que evidencia que, nas escolas, esses documentos nem sempre fazem eco nas práticas pedagógicas.

O padrão da heteronormatividade é reproduzido na escola configurando-se no que Foucault (1988) denominou de "ortopedia discursiva", o que consiste em uma estratégia biopolítica de controle da sexualidade baseada na norma heterossexual. Essa estratégia tem sido reproduzida em todos os níveis de ensino, como apontam os estudos dos autores Costa e Ribeiro (2011), Nardi e Quartiero (2012) e Seffner (2013). Neste sentido, serão apresentados alguns dados apontados pelos artigos analisados, os quais evidenciam a reprodução da heteronormatividade e seus efeitos.

Um dos elementos que se buscou observar, nos estudos categorizados, é se estes procuram apresentar subsídios teórico-metodológicos que permitam embasar as práticas educativas relacionadas à temática da diversidade sexual, bem como se essa análise considera as mudanças políticas e curriculares que emergiram após o ano de 1997, com a implementação dos PCN e demais documentos oficiais voltados à garantia dos direitos sexuais no contexto escolar.

Embora muitos artigos não explicitem a preocupação em fornecer subsídios para a construção das políticas públicas existentes, praticamente todos apresentaram perspectivas teóricas que instrumentalizam o profissional da educação com relação às práticas voltadas à garantia da diversidade sexual e dos direitos humanos. A perspectiva hegemônica, como mencionado anteriormente, é a pós-estruturalista, que, segundo Butler (2006) e Louro (2010), traz a desconstrução da lógica naturalizante da heterossexualidade, colocando em xeque a relação causal entre sexo biológico, gênero e orientação sexual. Os estudos analisados, em sua unanimidade, procuram dar um enfoque voltado à despatologização das sexualidades ao desconstruir a noção de normalidade dentro da sociedade.

Mas apesar de os estudos apresentarem, unanimemente, por parte dos autores, um enfoque voltado à despatologização das sexualidades, as informações presentes nos artigos analisados apontaram que a heteronormatividade ainda atravessa e constitui as práticas pedagógicas da escola. Nesse sentido, o estudo de Teixeira-Filho, Rondini e Bessa (2011), no qual foram entrevistados 2.282 estudantes do ensino médio, constatou que os jovens ainda reforçam, no espaço escolar, os discursos hegemônicos de controle da sexualidade, onde a heterossexualidade mantém-se como a única forma de inteligibilidade sexual na escola e a homofobia se institucionaliza como prática regulatória da construção social de identidades e gêneros.

Entre as dificuldades enfrentadas para pôr em prática as políticas públicas voltadas ao combate à homofobia e à valorização da diversidade, os estudos de Dinis (2008 e 2011), Avila e cols. (2011), Félix e Palafox (2009); Gesser e cols. (2012) Gomes (2006), Maia, Eidt, Terra e Maia (2012) Maia e cols. (2011); Quirino e Rocha (2012, 2013) e Rosistolato $(2009,2013)$ trouxeram a falta de formação

tradução nossa). 
dos docentes para trabalhar com a temática da sexualidade como um dos principais desafios a serem superados. Os autores acima destacam que a dificuldade dos professores em trabalhar a diversidade é atravessada por questões como suas crenças pessoais, a falta de conhecimento sobre a sua própria sexualidade, e o desconhecimento das diretrizes éticas adotadas pelo Estado para combater as discriminações sexuais e de gênero.

Outra dificuldade levantada no estudo de Furlani (2007) foi o fato de "as sexualidades", "os sexos" e "os gêneros" ainda serem pensados como "monstros" curriculares, marcados pela polêmica, pela provisoriedade e normalização nos currículos escolares. Neste sentido, o estudo de Silva (2011) apontou que a questão da diversidade ainda é um tema periférico ou mesmo relegado na academia, apesar de sua enorme importância para o conjunto da sociedade. Uma possível justificativa para a ausência dessa temática nos espaços coletivos, segundo as análises de Dinis (2011), seria o fato de as identidades sexuais ainda "pertencerem" ao domínio da vida privada.

Também apontado como um desafio, os estudos de Fontes (2008), Furlani (2007, 2008), Lionço e Diniz (2008), Rios e Santos (2008) e Vianna e Ramires (2008), buscavam analisar os livros didáticos distribuídos para a rede pública de ensino, sendo que quatro analisaram os materiais distribuídos pelo Programa Nacional do Livro Didático (PNLD) e pelo Programa Nacional do Livro Didático para o Ensino Médio (PNLEM). Todos os artigos questionavam o silêncio com relação à diversidade sexual nos livros, como a crítica apresentada por Fontes (2008) ao interpelar o fato de $70 \%$ dos livros distribuídos pelos programas mencionados acima se furtarem de exibir imagens que fizessem referência à homoafetividade, à representação dos homossexuais e às noções de família que destoassem das variações em torno da heteronormatividade. O silenciamento, segundo Furlani (2008), aparece como tentativa da norma em esconder aquilo que não se enquadra nos padrões ou até mesmo evitar que outros também desejem esse modo de ser. Entretanto, como afirmam Borges \& Meyer (2008, p.71), "sabe-se que este assunto está sempre em pauta, na sala de aula, nos corredores, nos banheiros, no pátio, nos corpos e nas mentes e, além de tudo, está sempre sendo ensinado através de olhares, sussurros, comentários, estímulos ou penalizações".

Outro estudo que contextualiza o modo como a diversidade sexual tem sido abordada na escola é o de Quartiero e Nardi (2011). Os autores realizaram a pesquisa em duas escolas da rede pública de Porto Alegre com o intuito de identificar como vem ocorrendo a implantação das políticas públicas voltadas à inclusão da diversidade sexual e de gênero nas práticas escolares. Os resultados obtidos indicaram que as práticas ainda são orientadas pela heteronormatividade, sendo as diferenças compreendidas como carência, desvantagem e desvio do indivíduo que necessita da intervenção do processo inclusivo. Além disso, embora o estudo tenha identificado que os professores se apropriaram dos discursos jurídicos de direitos humanos, direitos sexuais e direito à escolarização, as propostas de inclusão das escolas voltam-se para a prática de tolerância e tentativa de acabar com as diferenças, tendo como referência a normalidade.

$\mathrm{O}$ alto índice de alunos que relataram ter presenciado episódios de discriminação homofóbica, verificado na pesquisa de Asineli-Luz e Cunha (2011), sugere que tal ação contra os homossexuais parece ser uma ocorrência banalizada e corriqueira nos contextos escolares onde esses sujeitos estavam inseridos. A pesquisa de Avila e cols. (2011) mostrou que o desconhecimento das diretrizes éticas adotadas pelo Estado para combater as discriminações sexuais e de gênero por parte dos docentes envolvem tanto os processos de sua formação profissional quanto as suas crenças pessoais.

Por outro lado, foi verificado no estudo de Borges e Meyer (2008) que docentes participantes do curso "Educando para a Diversidade", ao buscarem capacitação que os auxiliasse a lidar com as questões vinculadas à sexualidade e homofobia na escola, tornaram-se vulneráveis perante o seu local de trabalho, seus colegas de profissão e familiares. Os autores perceberam, então, que a participação no curso de formação gerou a existência de um fenômeno denominado "pânico moral" o qual, na pesquisa por eles realizada, evidenciou-se pelo receio de contaminação e estimulação de uma sexualidade não hegemônica por parte dos docentes. $\mathrm{O}$ conceito de pânico moral, de acordo com Machado (2004), tem um caráter discursivo, transitório e performativo, portanto, capaz de produzir efeitos no cotidiano. Ademais, para a autora, este conceito se refere não somente à preocupação com propagação de determinado fenômeno, mas também a uma estratégia comunicacional adotada por determinados grupos de pressão, com vista a alcançar a 'voz' pública. Isso pode ajudar a explicar o porquê de os professores que realizaram o curso terem dificuldade de levar os ensinamentos para as escolas em que atuam uma vez que a heteronormatividade é predominante nesses espaços e assume um caráter performativo nos integrantes daquele contexto, dificultando a emergência de tensionamentos.

Analisando os artigos categorizados, foi possível constatar que, embora a produção do conhecimento relacionada à diversidade sexual na escola tenha avançado bastante na direção de uma educação inclusiva e que valoriza a expressão das diferenças, a realidade apresentada pelos artigos analisados ainda está aquém do que preconizam as políticas. Diante disso, evidencia-se a necessidade de aproximação do conhecimento produzido na academia com o cotidiano da escola.

\section{Considerações finais}

A partir das análises realizadas, identificou-se que, apesar de a diversidade sexual ser colocada como tema transversal nos currículos escolares brasileiros, ainda se percebe, na prática, uma abordagem biologicista e heteronormativa ao se trabalhar a orientação sexual. Os atores sociais da escola, como já observado nos estudos apresentados, conhecem superficialmente as diretrizes e reconhecem 
que necessitam de uma formação específica e continuada a respeito do assunto.

Com relação aos docentes, sugere-se a incorporação de discussões, por parte das escolas, sobre a temática de gênero, sexualidades e diversidades, acompanhadas de um processo contínuo de formação e sensibilização com os educadores. Também se evidencia a necessidade de materiais didáticos específicos que possam auxiliar os educadores a trabalharem o tema da sexualidade nas escolas, bem como o aperfeiçoamento daqueles que são distribuídos pelos programas políticos, no que diz respeito à omissão das diversidades.

Sobre as políticas públicas, observou-se que, apesar de muitos estudos estarem relacionados a elas, ainda se verifica a necessidade de mais pesquisas que levantem nacionalmente a efetividade de sua aplicação. Como ressaltam Assineli-Luz e Cunha (2011), embora as avaliações sobre intervenções pontuais sejam importantes para orientar o desenvolvimento de estratégias de intervenção baseadas em evidências, é relevante monitorar indicadores estatísticos, compreendendo que a melhoria da qualidade das escolas brasileiras não deve se concentrar somente na mudança positiva dos indicadores de desempenho acadêmico, mas também na redução da discriminação sofrida por determinados grupos.

Percebeu-se, na última década, a implementação de políticas públicas concomitante a uma maior discussão a respeito do tema na academia, gerando forças para a garantia de práticas voltadas aos direitos humanos. Hoje, o que ainda se verifica nas escolas são intervenções baseadas na lógica do senso comum, que só reiteram a norma e os preconceitos. A realidade encontrada na educação não condiz com o desenvolvimento da teorização legislativa e das intenções ético-políticas a ela atribuídas, não existindo, como verificado por Avila e cols. (2011), uma relação direta entre as leis e as ações.

Aponta-se como desafio a diminuição da distância entre a teoria e a prática, de modo que o conhecimento sobre o tema produza mudanças no cotidiano escolar. Destaca-se o desafio da implementação de uma cultura voltada à garantia dos direitos humanos nas escolas, que tenha como norte o acolhimento das diferentes expressões identitárias. Dessa forma, é possível transformar a escola num lugar de potência de vida para todos os sujeitos nela implicados.

Salienta-se também a relevância dos pontos levantados neste artigo para investigações futuras. Considerando que este estudo teve como objetivo realizar uma revisão bibliográfica acerca do tema diversidade sexual na escola, com enfoque em questões de gênero, foram identificados alguns tópicos que poderiam ser aprofundados.

Observou-se na categorização dos artigos desta revisão, certa escassez teórica acerca dos conjuntos de termos selecionados pela pesquisa. Segundo Rios (2009), as principais literaturas dedicadas à homossexualidade dialogam constantemente com a noção de gênero. Contudo, tal afirmação foi possível de ser constatada em apenas $45 \%$ dos trabalhos investigados. Além disso, marcadores como heterossexismo e heteronormatividade, indispensáveis ao diálogo sobre homofobia e discriminação, foram excepcionalmente elucidados, prejudicando a compreensão de quais lugares epistêmicos esses autores falam.

Destaca-se também a necessidade de se realizarem pesquisas que investiguem os efeitos produzidos pelas políticas públicas em nível nacional, bem como os principais fatores que limitam a sua execução, de modo que possam ser mapeados os pontos que devem ser reformulados. Outro desafio, para o qual a Psicologia tem muito a contribuir, refere-se à inclusão da dimensão subjetiva na implementação das políticas existentes. Isso se justifica porque os sujeitos da educação são atravessados e constituídos nas/pelas relações com os outros, e na intersecção com questões de raça, gênero, geração, religião, classe social e orientação sexual e, como não há dissociação entre pensar, sentir e agir (Gesser \& cols., 2012), é necessária a construção de estratégias que englobem todas essas dimensões.

\section{Referências}

Asinelli-Luz, A. \& Cunha, J. M. (2011). Percepções sobre a discriminação homofóbica entre concluintes do ensino médio no Brasil entre 2004 e 2008. Educar em Revista, (39), 87-102.

Alós, A. P. (2011). Gênero, epistemologia e performatividade: estratégias pedagógicas de subversão. Revista Estudos Feministas, 19 (2), 421-449.

Avila, A. H., Toneli, M. J. F., \& Andaló, C. S. A. (2011). Professores/as diante da sexualidade-gênero no cotidiano escolar. Psicologia em Estudo, 16 (2), 289-298.

Beiras, A., Tagliamento, G., \& Toneli, M. J. F. (2005). Crenças, valores e visões: trabalhando as dificuldades relacionadas a sexualidade e gênero no contexto escolar. Aletheia, (21), 69-78.

Bento, B. (2011). Na escola se aprende que a diferença faz a diferença. Revista Estudos Feministas, 19 (2), 549-559.

Borges, Z. N., \& Meyer, D. E. (2008). Limites e possibilidades de uma ação educativa na redução da vulnerabilidade à violência e à homofobia. Avaliação e Políticas Públicas em Educação, 16 (58), 59-76.

Brasil. Ministério da Educação. (1990). Estatuto da Criança e do Adolescente. Brasília: Secretaria de Direitos Humanos da Presidência da República. Recuperado: 04 ago 2016. Disponível: http://9cndca.sdh.gov.br/legislacao/Lei8069.pdf

Brasil. Ministério da Educação e do Desporto. (1998). Parâmetros Curriculares Nacionais: terceiro e quarto ciclos do ensino fundamental. Brasília: Secretaria de Educação Fundamental. Recuperado: 04 ago 2016. Disponível: http://portal.mec.gov.br/ seb/arquivos/pdf/introducao.pdf 
Brasil. (2004a). Plano Nacional de Políticas para as Mulheres. Brasília: Secretaria Especial de Políticas para as Mulheres. Recuperado: 04 ago 2016. Disponível: http://www.spm.gov.br/assuntos/pnpm/ plano-nacional-politicas-mulheres.pdf

Brasil. Ministério da Saúde. (2004b). Brasil sem Homofobia: Diretrizes do programa de combate à violência e à discriminação contra GLTB e promoção da cidadania homossexual. Brasília: Conselho Nacional de Combate à discriminação. Recuperado: 04 ago 2016. Disponível: http://bvsms.saude.gov.br/bvs/publicacoes/brasil_ sem_homofobia.pdf

Brasil. (2007). Decreto n. 6.286, de 5 de dezembro de 2007. Institui o Programa Saúde na Escola - PSE, e dá outras providências. Diário Oficial da União, Brasília, DF.

Brasil. Ministério da Saúde. (2008). Diretrizes para a Implantação do Projeto Saúde e Prevenção nas Escolas. Brasília: Secretaria de Vigilância em Saúde. Recuperado: 04 ago 2016. Disponível: http://bvsms.saude.gov.br/bvs/publicacoes/diretrizes_prevencao_ escolas.pdf

Brasil. (2009). Gênero e diversidade na escola: formação de professoras/es em Gênero, Orientação Sexual e Relações Étnico-Raciais. Livro de conteúdo. Rio de Janeiro: CEPESC; Brasília: SPM, 266 p. Recuperado: 04 ago 2016. Disponível: http:// estatico.cnpq.br/portal/premios/2014/ig/pdf/genero_diversidade_ escola_2009.pdf.

Brasil. (2012). Instituto Nacional De Estudos E Pesquisas Educacionais Em Educação Anísio Teixeira. Thesaurus brasileiro de educação. Recuperado: 03 ago 2016. Disponível: http://www. inep.gov.br/pesquisa/thesaurus.

Butler, J. (1999). Corpos que pesam: sobre os limites discursivos do 'sexo'. In G. L. Louro. (Org.), O corpo educado (pp. 151-172). Belo Horizonte, Autêntica.

Butler, J. (2006) Deshacer el género. Barcelona, Paidós Ibérica.

César, M. R. A. (2009). Gênero, sexualidade e educação: notas para uma "Epistemologia". Educar em Revista, (35), 37-51.

Costa. A. B. (2012). Preconceito contra orientações não heterossexuais no Brasil: critérios para avaliação. Dissertação Mestrado em Psicologia Social e Institucional, Universidade Federal do Rio Grande do Sul, Porto Alegre.

Costa, A. P. \& Ribeiro, P. R. M. (2011). Ser professora, ser mulher: um estudo sobre concepções de gênero e sexualidade para um grupo de alunas de pedagogia. Estudos Feministas, 19 (2), 475-489.

Cruz, E. F. (2011). Banheiros, travestis, relações de gênero e diferenças no cotidiano da escola São Paulo Revista Psicologia Política, 11 (21).

Dinis, N. F. (2008). Educação, relações de gênero e diversidade sexual. Educação \& Sociedade, 29 (103), 477-492.

Dinis, N. F. (2011). Homofobia e educação: quando a omissão também é signo de violência. Educar em Revista, (39), 39-50.

Fassin, E. (2009). La démocratie sexuelle contre elle-même. Vacarme, 48. Recuperado: fev 2015. Disponível: http://www. vacarme.org/ article1781.html.

Félix, R. G., \& Palafox, G. H. M. (2009). Relações de gênero na escola: só não vê quem não quer. Revista Iberoamericana de Educación, 50 (3), 2-13.

Ferrari, A., \& Almeida, M. A. (2012). Corpo, gênero e sexualidade nos registros de indisciplina. Educação \& Realidade, 37 (3), 865-885.

Figueiró, M.N.D. (2009). Educação Sexual: como ensinar no espaço da escola. Em M.N.D. Figueiró (Org.), Educação sexual: múltiplos temas, compromissos comuns (pp. 141-171). Londrina: UEL.

Fontes, M. (2008). Ilustrações do silêncio e da negação: a ausência de imagens da diversidade sexual em livros didáticos. Revista psicologia política, 8 (16), 363-378.

Foucault, M. (1988). História da sexualidade I: vontade de saber. (Albuquerque, M. T., Guilhon Albuquerque, J. A., Trad.). Rio de Janeiro: Edições Graal, v. 1.

Furlani, J. (2007). Sexos, sexualidades e gêneros: monstruosidades no currículo da Educação Sexual. Educar em revista, (46), 269-285.

Furlani, J. (2008). Mulheres só fazem amor com homens? A educação sexual e os relacionamentos entre pessoas do mesmo sexo. ProPosições, 19 (2), 111-131.

Gesser, M., Oltramari, L., Cord, D., \& Nuernberg, A. H. (2012). Psicologia escolar e formação continuada de professores em gênero e sexualidade. Psicologia Escolar e Educacional, 16 (2), 229-236.

Gesser, M., Oltramari, L. C., \& Panisson, G. (2015). Docência e concepções de sexualidade na educação básica. Psicologia \& Sociedade, 27(3), 558-568.

Girondi, J. B. \& Santos, S. M. V. (2011). Deficiência física em idosos e acessibilidade na atenção básica em saúde: revisão integrativa da literatura. Revista Gaúcha de Enfermagem, 32 (2), 378-84.

Gomes, V. L. O. (2006). A construção do feminino e do masculino no processo de cuidar crianças em pré-escolas. Texto \& Contexto Enfermagem, 15 (1), 35-42.

Junqueira, R. D. (2009). Homofobia nas escolas: um problema de todos. Em R. D. Junqueira (Org.), Diversidade sexual na educação: problematizações sobre homofobia nas escolas (pp. 13-51). Brasília: Ministério da Educação, Secretaria de Educação Continuada, Alfabetização e Diversidade, UNESCO. 
Lionço, T., \& Diniz, D. (2008). Homofobia, silêncio e naturalização: por uma narrativa da diversidade sexual. Revista Psicologia Política, 8 (16), 307-324.

Louro, G. L. (2001). Teoria queer uma política pós-identirária para a educação. Revista de Estudos Feministas, 2 (9), 541-553.

Louro, G. L. (1999). Pedagogias da Sexualidade. Em G. L. Louro (Org.), O corpo educado: Pedagogias da sexualidade (pp. 7-35). Belo Horizonte: Autêntica, 1999.

Maia, A. C. B., Eidt, N. M., Terra, B. M., \& Maia, G. L. (2012). Educação sexual na escola a partir da psicologia histórico-cultural. Psicologia em Estudo, 17 (1), 151-156.

Maia, A. C. B., Navarro, C., \& Maia, A. F. (2011). Relações entre gênero e escola no discurso de professoras do ensino fundamental. Psicologia da Educação, (32), 25-46.

Mariano, S. A. (2005). O sujeito do feminismo e o pós-estruturalismo. Estudos Feministas, 13(3), 483-505.

Machado, C. (2004). Pânico moral: para uma revisão do conceito. Interacções, 7, 60-80.

Meira, M. E. M., Queiroz, A. B., Oliveira, I. A., Moraes, R. Q., \& Oliveira, T. H. (2006). Psicologia Escolar, desenvolvimento humano e sexualidade: projetos de orientação sexual em instituições educacionais. Revista Ciência em Extensão, 2(2), 21.

Mendes, K. C. S., Silveira, R. C. P., \& Galvão, C. M. (2008). Revisão integrativa: método de pesquisa para a incorporação de evidências na saúde e na enfermagem. Texto \& Contexto Enfermagem, 17 (4), 758-764.

Nardi, H. C. (2008). O estatuto da diversidade sexual nas políticas de educação no Brasil e na França: a comparação como ferramenta de desnaturalização do cotidiano de pesquisa. Psicologia \& Sociedade, 20 (spe), 12-23.

Nardi, H. C., \& Quartiero, E. (2012). Educando para a diversidade: desafiando a moral sexual e construindo estratégias de combate à discriminação no cotidiano escolar. Sexualidad, Salud y Sociedad, (11), 59-87.

Quartiero, E. T. \& Nardi, H. C. (2011). A diversidade sexual na escola: produção de subjetividade e políticas públicas. Revista Mal-estar e Subjetividade, 11 (2), 701-725.

Quirino, G. S. \& Rocha, J. B. T. (2013). Prática docente em educação sexual em uma escola pública de Juazeiro do Norte, CE, Brasil. Ciência \& Educação, 19 (3), 677-694.

Quirino, G. S. \& Rocha, J. B. T. (2012). Sexualidade e educação sexual na percepção docente. Educar em Revista, (43), 205-224.

Rios, R. R. \& Santos, W. R. (2008). Diversidade sexual, educação e sociedade: reflexões a partir do Programa Nacional do Livro Didático. Revista Psicologia Política, 8 (16), 325-344.

Rios, R. R. (2009). Homofobia na Perspectiva dos Direitos Humanos e no Contexto dos Estudos sobre Preconceito e Discriminação. Em R. D. Junqueira (Org.), Diversidade sexual na educação: problematizações sobre homofobia nas escolas (pp. 53-83). Brasília: Ministério da Educação, Secretaria de Educação Continuada, Alfabetização e Diversidade, UNESCO.

Rohden, F. (2009). Gênero, sexualidade e raça/etnia: desafios transversais na formação do professor. Cadernos de Pesquisa, 39 (136), 157-174.

Rosistolato, R. (2013). "Você sabe como é, eles não estão acostumados com antropólogos!": uma análise etnográfica da formação de professores. Pro-Posições, 24 (2), 41-54.

Rosistolato, R. P. R. (2009). Gênero e cotidiano escolar: dilemas e perspectivas da intervenção escolar na socialização afetivo-sexual dos adolescentes. Revista Estudos Feministas, 17 (1), 11-30.

Seffner, F. (2013). Sigam-me os bons: apuros e aflições nos enfrentamentos ao regime da heteronormatividade no espaço escolar. Educação e Pesquisa, 39 (1), 145-159.

Silva, A. S. (2011). Políticas públicas, educação para os direitos humanos e diversidade sexual. Trivium - Estudos Interdisciplinares, $3(2), 58-72$.

Silveira, C. S. \& Zago, M. M. F. (2006). Pesquisa brasileira em enfermagem oncológica: uma revisão integrativa. Revista Latino Americana de Enfermagem, 14 (4). 614-619.

Teixeira-Filho, F. S., Rondini, C. A., \& Bessa, J. C. (2011). Reflexões sobre homofobia e educação em escolas do interior paulista. Educação e Pesquisa, 37 (4), 725-741.

Toneli, M. J. F. (2006). Homofobia em contextos jovens urbanos: contribuições dos estudos de gênero. Psic: revista da Vetor Editora, 7 (2), 31-38.

Vianna, C. \& Ramires, L. (2008). A eloqüência do silêncio: gênero e diversidade sexual nos conceitos de família veiculados por livros didáticos. Revista Psicologia Política, 8 (16), 345-362.

Wenetz, I. (2012). Gênero, corpo e sexualidade: negociações nas brincadeiras do pátio escolar. Cadernos CEDES, 32 (87), 199-210.

Wenetz,L., Stigger, M. P. \& Meyer, D. E. (2013). As (des)construções de gênero e sexualidade no recreio escolar. Revista Brasileira de Educação Física e Esporte, 27 (1),117-128.

Recebido em: 10/03/2015

Reformulado em: 24/03/2016

Aprovado em: 16/05/2016 


\section{Sobre as autoras}

Amanda Nogara Marcon (amnmarcon@gmail.com)

Graduada em Psicologia pela Universidade Federal de Santa Catarina - UFSC

Luísa Evangelista Vieira Prudêncio (luisa.evangelista.vp@gmail.com)

Graduanda do curso de Psicologia na Universidade Federal de Santa Catarina - UFSC

Marivete Gesser (marivete@yahoo.com.br)

Doutora em Psicologia e Professora do Programa de Pós-Graduação em Psicologia da Universidade Federal de Santa Catarina - UFSC

Políticas públicas e diversidade sexual * Amanda Nogara Marcon, Luísa Evangelista Vieira Prudêncio \& Marivete Gesser 
